Revista Docência do Ensino

Superior

v. 2, 2012

Inajara de Salles Viana Neves

UFMG

\section{PLANEJAMENTO EDUCACIONAL NO PERCURSO FORMATIVO}

\section{EDUCATIONAL PLANNING IN FORMATIVE PATH}

\section{RESUMO}

O planejamento precisa ser uma prática constante no trabalho docente, em especial no ensino superior. Mas o que fazer com a ementa e a bibliografia, como organizar as unidades programáticas? Precisamos refletir sobre o planejamento educacional para o reconhecimento de sua importância no resultado de cada semestre, ou seja, que os alunos desenvolvam minimamente os conhecimentos que são imprescindíveis naquela área de conhecimento. Discutiremos o conceito de planejamento, elementos que envolvem o processo de planejamento no ensino superior e as questões que foram discutidas no decorrer do percurso formativo 2010/2 no que concerne ao tema planejamento.

Palavras-Chave: Planejamento. Trabalho docente. Ensino superior.

\section{ABSTRACT}

The planning needs to be a constant practice in teaching particularly in higher education. But what to do with the menu and the bibliography, how to organize the program units? We need to reflect on educational planning in recognition of the importance of it in the end result of each semester, or minimally that students develop the skills that are essential in that field. We will discuss the concept of planning, elements that involve the planning process in higher education, and the questions that were discussed during the formative trajectory $2010 / 2$ regarding the planning issue.

Keywords: Planning. Teaching work. Higher education. 


\section{INTRODUÇÃO}

Discutir planejamento é um grande desafio, uma vez que planejar de forma sistematizada não costuma ser uma prática constante no trabalho docente, em especial no ensino superior.

Inicialmente, faz-se necessário refletir sobre como nos tornamos docentes no ensino superior, em que medida fomos orientados sobre a organização do trabalho, em especial no que concerne ao plano de ensino, verificação de ementas, gestão da sala de aula. Enfim, de modo geral nos tornamos professores na relação com nossos alunos e nas tentativas de erros e acertos no cotidiano da docência.

Essa é uma realidade que a maioria dos professores enfrenta quando inicia a carreira docente. O que fazer com a ementa e a bibliografia, como organizar as unidades programáticas? Na realidade, cada um faz "copiando" o plano que já estava pronto e, à medida que compreende melhor o eixo da disciplina que ministra, vai aperfeiçoando as unidades e suas escolhas avaliativas.

Quando iniciamos essa temática no Percurso Formativo do Ensino Superior, tínhamos como objetivo refletir sobre o planejamento educacional, não na perspectiva de uma organização empresarial, mas sim no reconhecimento de sua importância no resultado de cada semestre, ou seja, que os alunos desenvolvam minimamente os conhecimentos que são imprescindíveis naquela área de conhecimento. E, se o professor desconhecer ou não tiver muito claros os objetivos da disciplina, o aprendizado poderá não ser tão produtivo, e dependerá mais da subjetividade e empenho de cada aluno do que da condução do processo educacional que deve ser desencadeado pelo docente.

Neste artigo serão discutidos o conceito de planejamento, os elementos que envolvem o processo de planejamento no ensino superior e as questões que foram debatidas no decorrer do percurso formativo 2010/2 no que concerne ao tema planejamento.

\section{BREVE CONTEXTUALIZAÇÃO SOBRE O CONCEITO DE PLANEJAMENTO}

Num primeiro momento, pode parecer que discutir o conceito de planejamento seja algo desnecessário, uma vez que a grande maioria das pessoas entende que o mais importante seja a parte prática sobre o como fazer planejamento. Sabe-se que, uma vez que dominamos conceitualmente um assunto, as possibilidades de êxito ou inovação 
são maiores. Mais do que nunca, é importante destacar que o objetivo deste texto se refere ao trato do planejamento educacional no ensino superior. Diante desse contexto é papel do docente pensar sobre o processo de trabalho educacional, e isso não se faz sem fundamentação teórica e clareza conceitual. Considerando que não existe um conceito que seja mais correto que outro, optamos pela conceituação de acordo com o dicionário Houaiss:

serviço de preparação de um trabalho, de uma tarefa, com o estabelecimento de métodos convenientes; planificação; determinação de um conjunto de procedimentos, de ações (por uma empresa, um órgão do governo etc.), visando à realização de determinado projeto; planificação.

Podemos retirar desses significados três reflexões importantes:

- Planejamento demanda AÇÃO.

- Planejamento pressupõe "estabelecimento de métodos convenientes".

- Planejamento visa à "realização de determinado projeto".

No contexto em questão, planejamento é atitude, orienta-se por um método e visa a um resultado ou a um produto. Usando uma analogia, planejamento é a bússola de um viajante, que orienta seus passos e o faz chegar exitoso ao seu destino. Planejamento ajuda tanto os que estão envolvidos em sua realização quanto os que estão fora dele, por trazer informações importantes sobre para onde estão indo e como vão chegar lá. O planejamento orienta os docentes, os alunos, a coordenação, a instituição e a comunidade. O planejamento antecipa possíveis mudanças de rotas, faz previsão de tempo despendido, possibilita cálculos de prazos, valores, recursos, enfim, torna viável a execução/prática do Projeto Pedagógico de uma instituição.

A partir do exposto, percebem-se algumas limitações, pois nem sempre há relação entre o processo de elaboração e a possibilidade de realização. Essa lógica somente acontecerá à medida que os sujeitos se envolverem e se articularem com objetivo claro e preciso. Nesse sentido, de acordo com Vasconcellos (1995, p. 79):

[...] planejar é antecipar mentalmente uma ação a ser realizada e agir de acordo com o previsto. Planejar não é, pois, algo que se faz antes de agir, mas também agir em função daquilo que se pensou. Podemos fazer uma analogia com a coluna vertebral: é aquilo que dá postura ao sujeito, qual seja, não é algo característico só do antecedente da ação: está presente também na ação (e no depois).

Antecipar o que deve ser realizado é papel do professor universitário, para tanto, ele deve compreender todo o processo que envolve a organização do trabalho 
acadêmico que antecede a operacionalização do fazer da sala de aula. Mas o que envolve o planejamento na área educacional? Plano de Ensino é planejamento? Plano de Curso é planejamento dos professores ou dos coordenadores? Plano de aula faz parte de um planejamento no ensino superior? Quem planeja o quê? Para quem o professor faz planejamento?

\section{QUE ELEMENTOS ENVOLVEM O PROCESSO DE PLANEJAMENTO NO ENSINO SUPERIOR?}

Para se fazer planejamento, inicialmente é imprescindível ter uma leitura analítica da sociedade em que estamos inseridos, pois os alunos são influenciados constantemente pelos valores que nela estão inseridos. Além disso, é necessário ter conhecimento do sistema de ensino como um todo, e as concepções que norteiam a instituição em questão. Entre elas estão o Projeto Institucional ou Plano de Desenvolvimento Institucional (PDI), o Projeto ou Proposta Pedagógica do curso, o Plano de Curso ou Ensino, o processo avaliativo e então a realização da aula propriamente dita.

É importante detalharmos de forma breve sobre cada um dos elementos citados. O projeto institucional deve ser considerado norteador do processo de ensinoaprendizagem. O Projeto Pedagógico do curso deve ser organizado de modo coerente com a missão institucional e as normas gerais contidas no regimento da universidade. Sabe-se que nem sempre os docentes se apropriam das diretrizes e eixos contidos nesses documentos, mas um dos objetivos desse trabalho é mapear a estrutura do ensino superior, para que então seja possível um planejamento coeso e possível de ser colocado em prática.

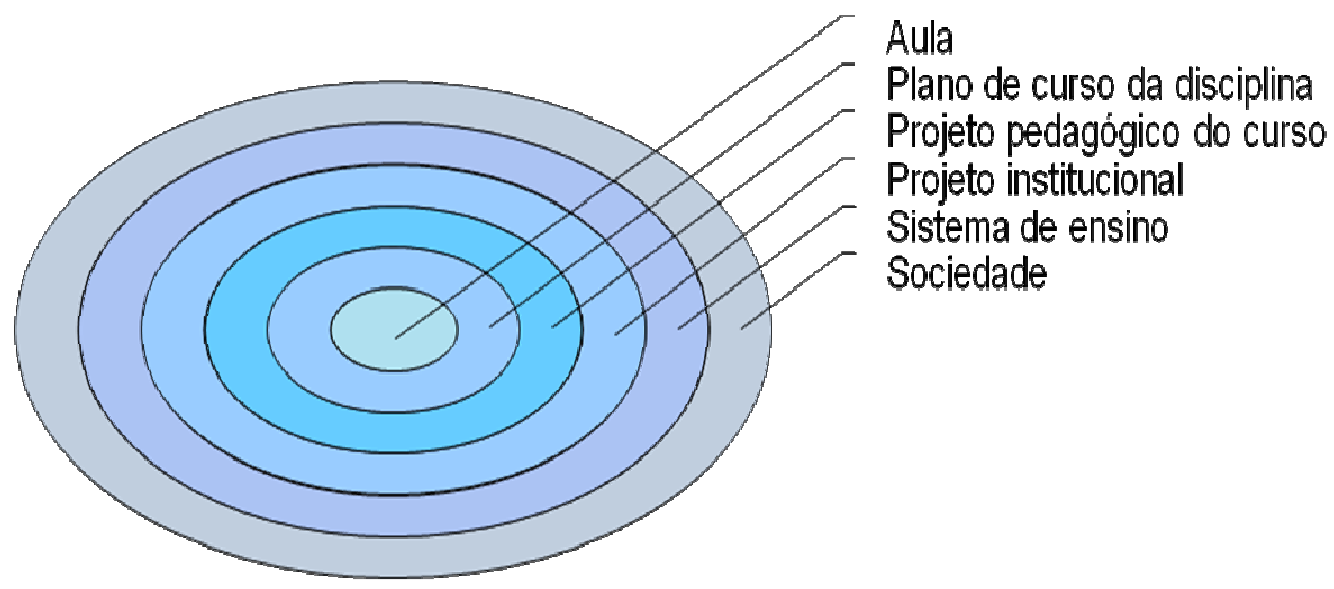

Figura 1 
A Proposta Pedagógica ou Projeto Pedagógico do curso é o grande "bloco" de superposição. Nele está contida toda a filosofia do curso, orienta toda a concepção de educação que a Instituição assume e norteia todas as ações pedagógicas a serem tomadas. A Proposta Pedagógica estabelece de que forma o conhecimento será construído no curso, como as disciplinas serão integradas, como será tratada a avaliação, como o curso será organizado. Um curso deve guardar coerência interna de estrutura, de filosofia, de proposta de formação dos cidadãos que está toda consolidada na Proposta Pedagógica. Existe uma razão para a disposição e a escolha das disciplinas. Existe uma coerência estabelecida na ordem em que as disciplinas são colocadas. Isso está embasado na Proposta Pedagógica. Ela é o DNA de um curso.

A Proposta Pedagógica é o documento que marca o início de um curso. Ela é elaborada por uma comissão de professores e coordenadores quando uma instituição se propõe a oferecer determinado curso. A partir do que está colocado na Proposta Pedagógica, o curso começa a existir e professores, alunos, coordenadores, instituição têm a tarefa de colocar em prática o que está no documento, têm a tarefa de fazer virar realidade o que foi colocado como "proposta". Aí os docentes têm, então, a tarefa de elaborar o Plano de Ensino, também chamado de Plano de Curso em algumas instituições.

O Plano de Ensino é o mapeamento de todas as ações que uma disciplina vai adotar para a sua realização. Ele prevê toda a condução que será dada a uma disciplina. Nele devem estar claros os objetivos que serão desenvolvidos e alcançados pelos alunos; os conteúdos que serão trabalhados e como serão distribuídos nas horas/aula disponíveis; as atividades que serão desenvolvidas; o processo avaliativo e as fontes de consulta que referendam a proposta da disciplina, ou a sua bibliografia. Os professores têm o dever de entregar o Plano de Ensino no começo do semestre/ano letivo e os alunos têm o direito de saber de que forma a disciplina será conduzida pelo professor e por eles mesmos. Ao tomar conhecimento do Plano de Ensino no início de uma disciplina, é possível fazer alguma alteração, acrescentar algum procedimento importante, conhecer as regras estabelecidas. Mas por onde começar na elaboração de um Plano de Ensino?

\section{QUAIS OS ELEMENTOS ESSENCIAIS NA ELABORAÇÃO UM PLANO DE CURSO/ENSINO?}

Conforme descrito anteriormente, quando iniciamos essa temática no Percurso Formativo do Ensino Superior, as questões até então apresentadas foram discutidas no ambi- 
ente virtual por meio de fórum (ambiente virtual) e grupo de trabalho (encontro presencial). Em princípio, pode-se aludir que planejamento é um assunto que interessa e ao mesmo tempo incomoda os professores. Foi possível perceber que diante da experiência vivenciada os professores participantes do Percurso Formativo apresentaram bastante interesse, conforme relato a seguir:

Planejar, eu planejo. Mas não consigo seguir os planos!

Este é o principal motivo para eu estar aqui neste fórum com vcs.

Às vezes me sinto sobrecarregada com muitos projetos. Entre a pesquisa, o ensino e a extensão tenho receio de deixar a desejar como docente, no desenvolvimento das aulas.

As pessoas costumam dizer: é só se planejar! mas eu acho que este "só" não é tão fácil assim.

Estou muito feliz com esta possibilidade de discutir o assunto com todos e todas vocês!

Percebe-se que esse "planejar" é exigido do docente, mas nem sempre são oferecidos os conhecimentos essenciais para que o professor planeje num contexto real e coerente e possível de ser colocado em prática. No momento inicial no fórum, alguns entenderam que as leituras sugeridas eram um pouco entediantes, entretanto, a maioria dos professores participou das discussões e apresentou relatos relevantes à discussão, conforme a seguir:

O texto de Vasconcellos foi muito útil, mas achei que o autor divagou muito e a leitura foi ficando chata do meio em diante. Isso não aconteceu com o capítulo do Gil ( Como planejar o ensino), bem mais prático e atraente do início ao fim.De qualquer forma, os dois me apresentaram conceitos úteis.

Acho que todo professor acaba planejando as aulas, de acordo com sua especialidade e realidade em que atua. Mas refletir a respeito disso vem me estimulando a buscar novos meios de alcançar meus objetivos didáticos e envolver os alunos.

Concordo também com um comentário de um dos colegas acima: é importante conhecer a história e os objetivos pessoais dos alunos que passam por nossas salas de aula. Do contrário, não conseguiremos integrá-los no processo de aprendizagem.

Discutir planejamento, com base em uma fundamentação teórica, facilitou e muito o processo no avanço da compreensão sobre o assunto, pois muitos dos docentes entendiam inicialmente que seriam passadas "dicas" ou questões técnicas sobre planejar. No momento do grupo de trabalho, sem deixar de refletir sobre o fazer e sobre como tem sido desenvolvido o trabalho docente, focamos a perspectiva prática, pensando no como fazer. O relato que será apresentado, apesar de extenso, retrata pelo menos em parte o que foi discutido no fórum e ao mesmo tempo denota como os professores 
se envolveram e compreenderam que planejar é muito mais que simplesmente organizar um cronograma.

Fico imensamente feliz com resultado do nosso fórum!!

Percebo que vocês estão buscando a fundamentação nos texto indicados, tanto o de referência GIL, A. C. Como planejar o ensino. In: GIL, Antônio Carlos. Didática do Ensino Superior. São Paulo: Atlas, 2007, p. 94-108,como no texto complementar VASCONCELLOS, C. S. Planejamento: plano de ensino-aprendizagem e projeto educativo. São Paulo: Libertad, 1995, p. 78-94 e 136-156.

Mais do que nunca, é primordial pensarmos que planejar prescinde em projetar nossas expectativas e saberes. Percebam que o planejamento é algo que está diretamente imbricado nas questões curriculares, avaliativas, metodológicas, tecnológicas. Todos os elementos, de algum modo, abordados pelos autores ou por vocês nos relatos remetem a essas questões. Nesse sentido, destaco aqui alguns questionamentos e ou afirmativas apresentados por vocês para dar continuidade às nossas discussões. Destaco aqui o questionamento da Prof. XX (Porque, na concepção da maioria, cumprir o programa é cumprir o que está no papel, e o papel não contempla a dinâmica da sala de aula. Como resolver esse impasse institucionalmente, se o plano entregue no início do semestre (o que está no papel) é aquele que, oficialmente, deve ser cumprido? Em que medida podemos alterar o plano conforme as necessidades sem descaracterizar a proposta inicial? Em que medida os alunos entendem que não estamos "fugindo" do programa, e sim adequando-o à realidade?) Planejar não significa de modo algum seguir de forma rígida e inflexível o que foi proposto, a perspectiva que destacamos aqui refere-se ao pensar junto com o aluno. Portanto, em algumas situações no decorrer do semestre surgem questões que não foram previstas, como por exemplo a turma ir além do que foi pensado no que concerne ao aprendizado, ou alguma dificuldade maior em relação a algum conceito. Em situações como essa, é imprescindível parar e reorganizar o cronograma junto aos alunos, destacando o motivo da pausa, ou da aceleração do processo. Quando o aluno participa do processo, mesmo que seja uma turma bastante jovem ou imatura, ainda assim ,há maior possibilidade de acertarmos do que quando simplesmente seguimos, apenas para cumprir o que foi proposto. Portanto, não há receita, há o contexto e a realidade da turma, o período, o curso e a disciplina. Considerando essas questões, podemos pensar de forma mais prática sobre como transformar o final do semestre mais produtivo. No mais, pessoal, vamos dar continuidade ainda a este fórum, no decorrer da semana, informarei quando o mesmo será encerrado, pois amanhã iniciaremos outra atividade, mas isso não quer dizer que esse espaço não possa continuar disponível.

Com o debate no fórum e a sistematização inicial do que foi apresentado pelos autores, bem como das demandas dos professores que participaram do percurso formativo, a temática continuou sendo discutida, e a partir de então passou-se a pensar em como de fato elaborar um Plano de Ensino, o que é necessário para que seja organi- 
zado para além de questões burocráticas e formais. Nesse sentido, retomamos a questão já apresentada anteriormente, isto é, por onde começar na elaboração de um Plano de Ensino? Inicialmente deve-se ter a ementa como elemento essencial e norteador do plano. Ela guarda a coerência do curso: horizontal, vertical, transversal. Ementa é uma descrição discursiva que resume o conteúdo conceitual/procedimental de uma disciplina. Pinheiro (1962, p. 48) descreve bem o significado de ementa. Segundo o autor, “o objetivo da ementa ou rubrica é o de permitir, em simples golpe de vista, o conhecimento do ato consultado". Mesmo sendo uma significação do termo para a área jurídica, essa definição nos ajuda a entender a ementa de uma disciplina, pois ela tem a função de apresentar de forma sucinta, num rápido relance, o que será pesquisado e estudado em uma disciplina.

A ementa é sintética, precisa e informativa. Ela é um bloco maciço: grandes unidades de tópicos num conjunto. A redação é contínua e os tópicos não são elencados em itens (um embaixo do outro). Os tópicos essenciais da matéria são apresentados sob a forma de frases nominais (frases sem verbo, sem artigos). Por guardar a coerência de um curso, a ementa não pode ser modificada pelos professores, a não ser que seja proposta da instituição atualizar ou mudar a Proposta Pedagógica do curso. Aí será formada uma comissão para este fim, constituída por professores, coordenadores, educadores. Ou seja, a mudança de uma ementa não é ato isolado de um professor.

A partir da compreensão de como se elabora uma ementa e de por que ela está disposta na Proposta Pedagógica, o docente deve se ater aos objetivos. Estes devem ser "pensados", apresentados, organizados a partir do que a ementa propõe. De modo geral, os objetivos das disciplinas estão dispostos na Proposta Pedagógica. Os objetivos (e ou as competências) podem ser acrescidos se o professor ou professora vislumbrar novas possibilidades de atuação do mesmo. Se o professor precisar elaborar os objetivos de uma disciplina, lembre-se de que os objetivos são ações a serem concretizadas pelos alunos. Os objetivos nortearão as ações do professor e orientará a forma de avaliar, ou seja, a avaliação será feita baseada no que foi proposto pelos objetivos, para verificar se foram alcançados ou não.

Estabeleça objetivos pensando em três conceitos:

- O conhecimento: o que os alunos têm de saber.

- A aplicação: o que os alunos vão fazer com o que aprenderam.

- Os valores: de que forma os alunos vão aplicar o que aprenderam. 
Exemplificando, veja os objetivos para a disciplina Comunicação Oral e Escrita de um curso de Administração:

- Distinguir os fatores internos (linguísticos) e externos (vinculados ao contexto histórico-social) que constituem o texto;

- Solucionar seus problemas diários de comunicação de forma objetiva e eficiente conforme os objetivos de sua atuação profissional;

- Favorecer a formação de uma visão crítica e criativa do uso do texto e da produção do texto.

Observe que o primeiro objetivo diz respeito ao conhecimento que o aluno vai adquirir. O segundo diz respeito ao que vai ser feito com o que foi aprendido e o terceiro se refere à forma como ele vai atuar.

Os objetivos apresentados são exemplos. Não quer dizer que seja necessário elaborar sempre três. A proposta é vislumbrar ações a serem concretizadas além de simples aquisição de conhecimento. Assim, ao pensar no processo avaliativo, as atividades vão além de verificar se o aluno adquiriu conhecimento, mas também de analisar se ele sabe o que fazer com o conhecimento que foi adquirido e de que forma vai atuar e se posicionar. Quando há clareza nos objetivos propostos, fica mais fácil organizar e distribuir os conteúdos previstos para a disciplina. Nesse caso, passamos a discussão para os aspectos voltados aos objetivos a serem alcançados pelos alunos ao longo do semestre/ano, é preciso distribuir os conteúdos nas horas/aula destinadas à disciplina. De novo voltamos à Proposta Pedagógica, pois foi lá que se determinou a quantidade de hora/aula para cada disciplina do curso. Os professores precisam prever todas as atividades que serão realizadas durante o desenrolar da disciplina. Haverá trabalho em grupo? Desenvolvimento de algum projeto? Visitas técnicas? Palestrantes? Aula de revisão? Apresentação de conceito e exercícios de fixação? Estudo de casos? Tudo isso precisa estar previsto nos dias letivos estabelecidos. O que vai orientar o professor na condução da apresentação dos conteúdos?

A bibliografia sugerida na Proposta Pedagógica também precisa ser contemplada. Ela determina qual autor será tomado como base para se trabalhar o conteúdo. A opção por um autor define uma linha de pensamento, um posicionamento teórico. Isso foi pensado no momento da construção do curso. Da mesma forma que a ementa, uma bibliografia não pode ser alterada sem o conhecimento da coordenação para que se analise se o novo autor é coerente com a linha de pensamento definida para o curso, além de ser um processo analisado e/ou aprovado pelo colegiado do curso. 
Além de todas essas questões, deve constar de forma muito transparente no Plano de Ensino como será o processo avaliativo do aluno. Em primeiro lugar, porque a avaliação só tem sentido se for para provocar uma reflexão no sujeito que está sendo avaliado. Em outras palavras, a avaliação deve permitir ao aluno ter informações, não apenas para identificar o seu estágio de evolução, mas para melhorar a si mesmo, ativando funções críticas autônomas de conhecimento de tal evolução, daquilo que faz e de como faz. A avaliação precisa ser importante para o sujeito avaliado, para que ele a tome como um instrumento de desenvolvimento pessoal.

Assim, é necessário ficar muito claro, tanto para o aluno quanto para o professor, como será o processo avaliativo naquele semestre/ano. De que forma será feita a avaliação processual? De que forma será feita a avaliação pontual? Quantos trabalhos? Quantas provas? Haverá perda de pontos se as datas não forem cumpridas? Haverá segunda chance? Ou seja, quando se estabelecem todas as regras válidas para o trabalho que vai se desenvolver no semestre/ano, ficam explícitas também a seriedade e a justiça que vão pautar essa condução. Evita-se o desgaste tão constante nas salas de aulas, por causa da má condução e da falta de transparência do Processo Avaliativo. Ao contrário, deixar transparente todo o processo avaliativo é dar o real significado da avaliação, de que ela é uma atitude essencial de quem está no percurso, de quem precisa saber como está e de que forma pode se apropriar ainda mais do conhecimento. Quando o processo avaliativo está claro para os alunos, ele deixa de ser um jogo de poder entre docentes e discentes.

\section{CONSIDERAÇÕES POSSÍVEIS}

Entende-se que a proposta do curso em questão já se apresenta como uma prática inovadora. Discutir diferentes temáticas que perpassam o trabalho docente se faz cada vez mais uma necessidade urgente. Foi possível perceber na experiência específica voltada para temática planejamento que os professores têm grande interesse em compreender melhor o processo. Mas na maioria das vezes estão mais voltados para as questões práticas do que conceituais envolvidas no planejamento. Diante da realidade encontrada, foi possível verificar situações em que não há objetivos nos planos de ensino e os conteúdos programáticos são confundidos com cronograma. A verificação desses fatos não é fator passível de crítica, mas sim de se pensar que é papel das instituições proporcionar possibilidades de formação específica para o professor do ensino superior. Na grande maioria das áreas os professores possuem grande domínio do con- 
teúdo técnico, mas faltam-lhes oportunidades de reflexão sobre questões metodológicas, curriculares, avaliativas e de planejamento. Entende-se que os professores que fizeram parte desta experiência foram ousados, pois se desafiaram a cumprir várias atividades, em um curto espaço de tempo, no meio do semestre letivo, utilizando o ambiente virtual de aprendizagem Moodle, que nem todos dominavam. Nesse sentido, parabenizo a todos pelo empenho e pelo desejo de trocar saberes por meio das nossas discussões.

\section{REFERÊNCIAS}

CUNHA, M. I. Reflexões e práticas em pedagogia universitária. Campinas: Papirus, 2007.

GIL, A. C. Como planejar o ensino. In: GIL, Antônio Carlos. Didática do Ensino Superior. São Paulo: Atlas, 2007. p. 94-108.

HOUAISS, A. Dicionário eletrônico da língua portuguesa. Rio de Janeiro: Objetiva, 2001.

JOLY, M. C. R. A.; SANTOS, A. A. A. dos; SANTOS, F. F. (Org.) Itens do cotidiano universitário. São Paulo: Casa do Psicólogo, 2005.

MASSETO, M. T. Competência pedagógica do professor universitário. São Paulo: Summus, 2003.

MATTOS, Lúcia. Avaliação da aprendizagem acadêmica. Belo Horizonte: FEAD, 2005.

MATTOS, Lúcia. Planejando a aula no ensino superior: estratégias didáticas e recursos tecnológicos que dinamizam a aprendizagem. Belo Horizonte: FEAD, 2005.

MORAIS, M. M. A sala de aula no contexto da educação do século 21. Brasília: Inep, 2005.

PINHEIRO, H. F. Técnica legislativa. 2. ed. Rio de Janeiro; São Paulo: Freitas Bastos, 1962.

VASCONCELLOS, C. S. Planejamento: plano de ensino-aprendizagem e projeto educativo. São Paulo: Libertad, 1995.

VEIGA, I. P. A.; CASTANHO, M. E. L. M. Pedagogia universitária: a aula em foco. Campinas: Pairos, 2000.

TEODORO, A.; VASCONCELOS, M. L. Ensinar e aprender no ensino superior: por uma epistemologia da curiosidade na formação universitária. São Paulo: Mackenzie:Cortez, 2003.

ZABALZA, M.A. O ensino universitário: seu cenário e seus protagonistas. Porto Alegre: Artmed, 2004. 